\title{
Perspectives of Pregnant Women Regarding Iron Deficiency Anemia
}

\author{
Sirikanok Klankhajhon', Kornkarn Pansuwan', Kanokon Klayjan'1, Somsak Thojampa' and \\ Nannaphat Nensat ${ }^{2}$
}

1 Faculty of Nursing, Naresuan University, Phitsanulok, Thailand

2 Watbot Hospital, Phitsanulok, Thailand

\begin{abstract}
Introduction: Iron deficiency anemia (IDA) is a global health problem. The prevalence of anemia in pregnancy worldwide is nearly half of pregnant women. It impacts on women and offspring outcomes during pregnancy, intrapartum and postpartum period associated with increasing rate of preterm labor, pregnancy induced hypertension, low birth weight, perinatal death including postpartum hemorrhage, postpartum infection, unsuccessful rate of exclusive breast feeding, and postpartum depression. Inadequate iron intake, maternal physiological changes during pregnancy, and bleeding were indicated as common causes of IDA in pregnancy. The objective was to explore the experiences of pregnant women regarding IDA.
\end{abstract}

Methods: A total of eighteen women between 16-36 weeks' gestation participated in the qualitative research. Women were selected by purposive sampling according to inclusion criteria to in-depth interviewed at antenatal care clinic, Watbot hospital, Phitsanulok, Thailand.

Results: Thematic analysis of the qualitative interviews identified four main themes: iron-deficiency anemia in pregnant as a normal pregnancy; concern on food rather than hematocrit (HCT) level; maternal instinct in healthy baby; and low socioeconomic as a main obstacle.

Conclusion: The findings illustrated to enhance better understanding the nature, attitude, knowledge, perception, and behavior of pregnant women on IDA, facilitators to support women for healthy behavior, and barriers to IDA in pregnancy based on Thai context.

\section{ARTICLE HISTORY}

Received: June 06, 2021

Accepted: September 09, 2021

\section{KEYWORDS}

iron deficiency anemia; pregnant women

\section{CONTACT}

Sirikanok Klankhajhon $\triangle$ sirikanok k@hotmail.com $\doteq$ Faculty of Nursing, Naresuan University, Phitsanulok, Thailand

Cite this as: Klankhajhon, S., Pansuwan, K., Klayjan, K., Thojampa, S., \& Nensat, N. (2021). Perspectives of Pregnant Women Regarding Iron Deficiency Anemia. Jurnal Ners, 16(2). 119-127. doi:http://dx.doi.org/10.20473/jn.v16i2.27418

\section{INTRODUCTION}

Iron deficiency anemia (IDA) in pregnant women is a serious global health issue (WHO, 2011). Anemia in pregnant women is defined as the Hemoglobin $(\mathrm{Hb})$ level lower than $11 \mathrm{~g} / \mathrm{dL}$ or Hematocrit (Hct) level lower than 33\%, divided into three classifications of severity as follows: mild (Hb10-10.9 g/dL), moderate ( $\mathrm{Hb} 7-9.9 \mathrm{~g} / \mathrm{dL}$ ) and severe $(\mathrm{Hb}<7 \mathrm{~g} / \mathrm{dL}$ ) (Center of Disease Control (CDC), 1989; WHO, 2011). The Center of Disease Control defined the severity of anemia in each trimester AS Hb level lower than $11 \mathrm{~g} / \mathrm{dL}$ or Hct level lower than 33\% in the first and third trimester of pregnancy and Hb level lower than $10.5 \mathrm{~g} / \mathrm{dL}$ or Hct level lower than $32 \%$ in the second trimester of pregnancy due to the physiological changes during pregnancy (Center of Disease Control, 1989).

The Global Health Observatory (GHO) reports indicated that the prevalence of anemia worldwide is increasing WITH around 40\% of pregnant women in 2016 (Murray-Kolb et al., 2012; WHO, 2011,, 2016). One of five cases of anemia in pregnant women is caused by iron deficiency anemia (IDA) (Department of Health, 2017, 2018; WHO, 2011). IDA in pregnant women has direct and indirect impacts on maternal health and offspring outcomes, including both medical and obstetrical complications during pregnancy, labor, and postpartum period. It is associated with increasing rate of preterm labor, pregnancy induced hypertension, low birth weight, perinatal death, postpartum hemorrhage, 
postpartum infection, unsuccessful rate of exclusive breast feeding, and postpartum depression (American College of Obstetricians and Gynecologists (ACOG), 2008; Camaschella, 2015; Maha et al., 2011; Tandon et al., 2018).

The evidence strongly supports that maternal physiological changes during pregnancy with inadequate iron intake are indicated as common causes of IDA in pregnancy (Camaschella, 2015; Goonewardene et al., 2012; Lowdermilk et al., 2016; Pinchaleaw, 2017; Reinold et al., 2012; Tana, 2017; Techakampholsarakit et al., 2018). In Thailand, the policy promotes to decrease rate of IDA in pregnant women by the Department of Health (DoH), Ministry of Public Health (MoPH) that provides iron supplement for all pregnant women. including nurses use in the nursing processes with group and individual health education about IDA such as severity, consequences, prevention, treatment, dietary and iron supplement, and self-care during pregnancy (Bureau of Nutrition, Department of Health, 2011; Center of Disease Control, 1989; Department of Health, 2018; Food Division, Bureau of Food, Food and Drug Administration, 2016) and based on the recommendation from the World Health Organization (WHO, 2016) processes may support and decrease rate of IDA in pregnant women.

In addition, most of the studies focused on the risk factors, intervention, and program to prevent and improve the iron deficiency anemia in pregnant women (Kaljarueg, 2017; Sookdee \& Wanaratwichit, 2016; Sukkai \& Khiewyoo, 2012). The national statistics reports that IDA in Thai pregnant women was around 20.43\%, 21.05\%, 20.39\%, 18.55\%, 17\%, and $17 \%$, respectively, from 2013 to 2018 (Department of Health, 2017; 2018). Although, the prevalence of IDA in pregnant women slightly decreased, it is quite steady around $17 \%$. It is still more than KPI for anemia in pregnancy. The key performance indicator (KPI) must be less than $10 \%$ for anemia in pregnancy. The prevalence of anemia in Thai pregnant women is still higher than the KPI of anemia in pregnant women. These data illustrated the current studies that focused on the intervention to prevent and improve the iron deficiency anemia in pregnant women. It might not fit with the women's views, which affect the practical use for pregnant women with IDA. Therefore, the overall aim of the study was to explore the experiences and perspectives of pregnant women regarding IDA to understand their attitude, knowledge, and behavior during pregnancy based on the Thai context including their insight of barriers and facilitators to anemia in pregnant women. This identification of phenomena and experiences of pregnant women with IDA will be used to design the program or intervention that might fit and be of practical use for them.

\section{MATERIALS AND METHODS}

A phenomenology qualitative research was used to explore the experiences and understand the phenomena of pregnant women with IDA through indepth interviews. Their experiences provided better understanding of the attitude, knowledge, self-care and behavior of pregnant women and provided insights into their experiences of the barriers and facilitators based on the Thai context.

A target sample size was ten to fifteen pregnant women for interviews. The researcher believes the number of sample size around ten to fifteen women is sufficient to identify and understand the phenomena and their lived experiences of pregnant women with IDA (Creswell, 2014; Holloway, 2010). The sampling grid is shown in Table 1. Women were selected by purposive sampling for in-depth interview at antenatal care clinic, Watbot hospital, Phitsanulok, Thailand. Women were initially invited by the nurse at ANC. When a pregnant woman expressed willingness to participate in the interviews, they contacted the researcher by telephone (free call) or in person at the ANC during office hours. Then, women interested in participation were given full information by the researcher. The researcher took written consent. The participants were screened through inclusion and exclusion criteria. The inclusion criteria are woman able to read, speak and understand the Thai language. Pregnant women diagnosed as IDA, who had Hct level less than 33 percentages, and no complications would be eligible for recruitment. Women with any complications and extremely high stress scores (ST-5 score $>8$ points) during pregnancy were excluded. Women with extremely high stress scores were referred to nurse at ANC. ST-5 is a stress self-assessment tool within the Thai version of the mother and child health handbook. Stress score was collected from the women as part of their usual antenatal clinical assessments and these data were then extracted by the researcher. Participants were offered a gift voucher of 200 baht for taking part in the interviews.

The data were collected through individual indepth interviews from February to September 2020. The semi-structured questions were developed by the researcher based on the concepts of anemia in

Table 1. Purposive Sampling Frame for Pregnant Women in the Interviews

\begin{tabular}{lll}
\hline \multicolumn{1}{c}{ Variable } & \multicolumn{1}{c}{ Details of variable } \\
\hline Number of pregnancy & Primigravida (first time) & Multigravida (second or more) \\
Maternal age & Age $<20$ years old & Age $\geq 20$ years old \\
History of IDA during pregnancy & Yes & No \\
Gestational age (GA) at the first visit & $>12$ weeks & $<12$ weeks \\
Antenatal care visit at clinic following the recommendation & Yes & No \\
Severity of anaemia & $\mathrm{Hb}<7 \mathrm{~g} / \mathrm{dL}$ & $\mathrm{Hb}>7 \mathrm{~g} / \mathrm{dL}$ \\
\hline
\end{tabular}


pregnancy, research objective, and context. The items of questions were verified by the three experts in maternal and newborn nursing in terms of content, construct, and language. The question guide consisted of the participant's experiences with the IDA during pregnancy, caring during pregnancy, facilitators and barriers related the IDA and healthcare service. For example, the key questions were guided to in-depth interview: "Could you tell me about your experiences during pregnancy?"; "Could you tell me about your current Hct level?"; and "I would like to start with your usual care, please tell me about what do you do during pregnancy with IDA." Steps in conducting the interviews were as follows: (1) the name, position and contact details of the researcher were introduced to the participants; (2) study information was briefed to the participants on the purposes, benefits and processes of the study, and ethical issues; (3) any questions from the participants were answered by the researcher before starting the interviews; and (4) the main findings from the interviews were summarized for checking accuracy and correction with the participants (Creswell, 2014; Holloway, 2010). The interviews ended with eliciting the participant's demographic characteristics. All interviews took about 30 to 45 minutes per participant and were recorded with a digital voice recorder and field notes.

Thematic analysis was used to analyze data. The data were managed by the researcher as well as manually. The processes in conducting a thematic analysis were as follows (Braun\& Clarke, 2006; Creswell, 2014; Holloway, 2010). Firstly, the data were fully transcribed. The full transcripts were checked and cross-checked for accuracy. Next, all transcripts were read and reread several times to understand each interview in depth. The data were compared for similarities and differences among participants based on a list of all topics from interviews. Verbatim quotes were underlined and highlighted as key words. The data contents were coded. The codes were checked back with the transcripts for accuracy. The codes were grouped according to initial categories and progressed to subthemes and themes. The themes were examined in terms of relationships in two dimensions between data set and codes; and codes and themes. The themes were defined and named for presenting the overall data in each theme. Lastly, the coding and the themes were examined for accuracy by the researcher, co-researcher and consultant. The process of thematic analysis was reported in relation to the research questions and literature. For instance, the data were transcribed as:

"I feel nothing. I had morning sickness and fatigue in the early pregnancy. It is normal signs and symptoms of pregnancy." ( $\left(\mathrm{G}_{1} \mathrm{P}_{0}\right.$, Age 34 years, GA 30 wk., $\mathrm{Hb} 9 \mathrm{~g} / \mathrm{dL}$ )

"I have had an anemia before as same as this time. I feel nothing. It is a normal, just low level of Hct. I never had signs of anemia." ( $\mathrm{G}_{3} \mathrm{P}_{2} \mathrm{~L}_{2}$, Age 30 years, GA 32 wk., Hb 8.5 g/dL)

The verbatim quotes were underlined and highlighted as keywords as "never had signs of anemia" and "a normal signs and symptoms of pregnancy." The data contents were coded and then were examined into the theme.

The study rigor was obtained in terms of trustworthiness through credibility, confirmability, objectivity and transferability (Anney, 2014). The process of qualitative interviews was checked by consolidated criteria for reporting qualitative studies (COREQ) in three domains: research team and reflexivity; study design; and analysis and findings. The researcher summarized the findings from the interviews, which were re-examined by the researcher, co-researcher and consultant in each phase of the data analysis, including codes and themes as a peer-debriefing for credibility (Anney, 2014). The protocols of data collection and data analysis were checked with the researcher, coresearcher and consultant to ensure that they were described well enough in terms of data collection process, raw data, process of data analysis and interpretation of the findings as an audit trial for dependability.

The methods of data collection and data analysis process were reported in rich description of characteristics with the details of research setting, characteristics of participants, and the Thai context. The decision-making of the researcher in each stage was demonstrated so that the research processes and context of the study can be applicable for justification to other contexts or situations in future research as a transferability (Anney, 2014; Baillie, 2015; Creswell, 2014). The research process was recorded with a diary by the researcher including the feelings and contexts behind the decision-making for confirmability. The effect of the researcher on the research process was recognized because the researcher as an instrument might influence the process of the data collection and data analysis. The data analysis process was demonstrated in rich description to ensure that the findings were interpreted from the interviews (Anney, 2014; Baillie, 2015; Creswell, 2014; Shenton, 2004).

Ethical approval for this study was obtained from the Naresuan University Institution Review Board, Naresuan University, Thailand (IRB No. 0596/62) dated on October 08, 2019. The decision to participate was made by individual women independently and without pressure. Pregnant women could withdraw any time without giving any reason and their withdrawal from the research did not affect the standard of care. All data in this study were identified by individual codes, except for copies of the consent form which contained the names and contact details of all participants. No data could be accessed by anyone other than the researcher, co-researcher and consultant. The data were presented and reported without personal identification. During data collection 
and analysis, the researcher used a personal laptop with strong password protection. All files and documents were kept securely in locked storage at Naresuan University, Thailand. Personal information will be kept for one year after the end of the study; all other anonymized data will be kept for a period of ten years after completion of the study in locked storage at Naresuan University, Thailand.

\section{RESULTS}

A total of twenty-five pregnant women had expressed an interest in participating in the in-depth interviews. Five women withdrew from the study due to their duties: taking care of their children, transportation and their households. Two women withdrew from the interviews due to their mother and husband having not allowed them to participate in the interviews. They also decided after the introduction to have explained again the aim of the study, the interview process, and checked consent for recording the interviews. One woman's mother said, "It takes quite a time and there's nothing for us to do that"; and the husband said, "It's not significant to us. We just go back home to prepare our street food: Thai sweets."

The participants were residents of the Lower Northern region of Thailand such as Sukhothai, Pichit, Phitsanulok, and Tak in both the rural (village or countryside) and urban (town) areas. The

Table 2. Demographic characteristics of pregnant women in the in-depth interviews

\begin{tabular}{|c|c|c|}
\hline Characteristics & $\mathbf{n}$ & $\%$ \\
\hline \multicolumn{3}{|l|}{ Age } \\
\hline$<20$ years & 5 & 27.8 \\
\hline 20-34 years & 9 & 50.0 \\
\hline$\geq 35$ years & 4 & 22.2 \\
\hline \multicolumn{3}{|l|}{ Number of gravida } \\
\hline Primigravidarum & 8 & 44.4 \\
\hline Multigravidarum & 10 & 55.6 \\
\hline \multicolumn{3}{|l|}{ Occupation } \\
\hline Employee & 4 & 22.2 \\
\hline Self-employed & 3 & 16.6 \\
\hline Agricultural & 5 & 27.8 \\
\hline Housewife & 6 & 33.4 \\
\hline \multicolumn{3}{|l|}{ Education } \\
\hline Secondary school or equal & 9 & 50.0 \\
\hline High school or college degree & 6 & 33.4 \\
\hline Bachelor degree or equal & 3 & 16.6 \\
\hline \multicolumn{3}{|l|}{ Pre-pregnancy Body Mass Index (BMI) } \\
\hline Underweight (BMI < 18.5 kg/m2) & 3 & 16.6 \\
\hline Healthy (BMI 18.5-22.9 kg/m2) & 10 & 55.6 \\
\hline Overweight (BMI 23-29.9 kg/m2) & 5 & 27.8 \\
\hline \multicolumn{3}{|l|}{ Income } \\
\hline$<200$ US dollar & 3 & 16.6 \\
\hline 200-400 US dollar & 6 & 33.4 \\
\hline 400-800 US dollar & 6 & 33.4 \\
\hline >800 US dollar & 3 & 16.6 \\
\hline \multicolumn{3}{|l|}{ Gestational age at the first ANC } \\
\hline$\leq 12$ weeks & 11 & 61.1 \\
\hline$>12$ weeks & 7 & 38.9 \\
\hline \multicolumn{3}{|l|}{ Hb Level } \\
\hline$<7 \mathrm{~g} / \mathrm{dL}$ & 2 & 11.1 \\
\hline $7-9.9 \mathrm{~g} / \mathrm{dL}$ & 4 & 22.2 \\
\hline $10-10.9 \mathrm{~g} / \mathrm{dL}$ & 12 & 66.7 \\
\hline
\end{tabular}

demographic characteristics of pregnant women are summarized in Table 2. The age of participants ranged from 16 to 40 years. The average income of participants was 10,000 baht a month. Around half of participants had a healthy pre-pregnancy BMI (10, $55.6 \%)$, five women had an overweight (27.8\%) and three women had an underweight (16.6\%). Most of the pregnant women had a mild severity of IDA ( $\mathrm{Hb}$ $10-10.9 \mathrm{~g} / \mathrm{dL})(\mathrm{n}=13 ; 66.7 \%)$. They had no signs and symptoms of IDA.

Topics of in-depth interviews covered a range of issues on pregnancy and IDA. There were an initial twelve codes and initial nine sub-themes. These are shown in Figure 1. Four main themes emerged from the interviews: iron-deficiency anemia in pregnant women as a normal pregnancy; concern on food rather than Hct level; maternal instinct in healthy baby; and low socioeconomics as a main obstacle.

\section{Theme 1: Iron-deficiency anemia in pregnant women as a normal pregnancy}

This theme illustrates the perception of pregnant women with IDA. Their point of views was still feeling it as a normal pregnancy even though they have had an anemia during pregnancy. They said:

"I feel as the same as I am a normal pregnant woman. I know, I have a hematocrit level quite lower than usual pregnant women." ( $\mathrm{G}_{1} \mathrm{P}_{0}$, Age 18 years, GA 32 wk., Hb 6 g/dL)

"When I was pregnant with the last child, this time, I feel the same as well." $\left(\mathrm{G}_{3} \mathrm{P}_{2} \mathrm{~A}_{0} \mathrm{~L}_{2}\right.$, Age 32 years, $\mathrm{GA}$ 28 wk., Hb 7 g/dL)

Pregnant women perceive the IDA in the real word as quite different impacts from information from healthcare professionals.

"I got information from the nurse and doctor at this hospital. They also said that my baby will have growth restriction. It means like a small baby but when the doctor checked my baby via ultrasound, she told me the size of baby is appropriate with my gestation. So, I feel IDA for me as a normal." ( $\mathrm{G}_{2} \mathrm{P}_{1} \mathrm{~A}_{0} \mathrm{~L}_{1}$, Age 27 years, GA 30 wk., Hb 10 g/dL).

\section{Sub-theme 1.1: Nothing: not any signs and symptoms}

Pregnant women expressed their experiences about IDA during pregnancy. They indicated that they have not had any signs and symptoms and related complications of IDA such as severe fatigue, abortion, infection, baby low birth weight, preterm labor, and others.

"I'm OK. I don't have any signs and symptoms about anemia that the nurses at the antenatal clinic told me about, such as infection, abortion, and intrauterine growth retardation. I am aware and take care myself and my baby the same as in the previous pregnancy. I just have an anemia in this pregnancy. Last pregnancy, I am not sure, I have Hct 
level around 35-37 vol\%." (G4 $\mathrm{G}_{4} \mathrm{P}_{2} \mathrm{~A}_{1} \mathrm{~L}_{2}$, Age 42 years, GA 34 wk., Hb 8 g/dL)

"I feel nothing. I had morning sickness and fatigue in the early pregnancy. It is normal signs and symptoms of pregnancy." $\left(\mathrm{G}_{1} \mathrm{P}_{0}\right.$, Age 34 years, GA 30 wk., $\mathrm{Hb} 9 \mathrm{~g} / \mathrm{dL}$ )

"I have had anemia before, same as this time. I feel nothing. It is normal, just low level of Hct. I never had signs of anemia." $\left(\mathrm{G}_{3} \mathrm{P}_{2} \mathrm{~L}_{2}\right.$, Age 30 years, GA 32 wk., $\mathrm{Hb} 8.5 \mathrm{~g} / \mathrm{dL}$ )

\section{Sub-theme 1.2: Common way of life during pregnancy}

Participants indicated their lifestyle during pregnancy with IDA as similar as the common way of life during pregnancy. They expressed that they can run their job, take care of their children, household, and come to the hospital by themselves.

"I feel as similar as other pregnant women because I can do my job at the convenience store and household including take care of my husband. I feel the nurse and doctor care for me the same as normal pregnancy." $\left(\mathrm{G}_{1} \mathrm{P}_{0}\right.$, Age 34 years, GA 30 wk., $\mathrm{Hb} 9 \mathrm{~g} / \mathrm{dL})$

"I have two children at 9 and 5 years old. I take care of this pregnancy the same as normal. Now, I am a single mom. I think, I have a common way of life as a normal pregnancy although I have anemia during pregnancy. It's just anemia, it's the same as normal pregnancy. I do it as my usual life during pregnancy. I also got iron supplement the same as normal pregnancy." ( $\mathrm{G}_{4} \mathrm{P}_{2} \mathrm{~A}_{1} \mathrm{~L} 2$, Age 42 years, GA 34 wk., $\mathrm{Hb}$ $8 \mathrm{~g} / \mathrm{dL})$
They illustrated that they also work, live, and do other things during pregnancy with IDA the same as pregnant women without IDA, including getting iron supplement.

\section{Theme 2: Concern on food rather than Hct level}

This theme illustrates the pregnant women's concern on their food and diet as related to their gestational weight gain. They expressed that when they got information from the nurse about their complication: IDA during pregnancy, they were concerned about their usual food, that they should take more food such as milk, vegetables, eggs, and meat. Surprisingly, they did not concern to take iron-rich food such as pork liver, broccoli, green bean, and pork blood.

"When I know, I am a pregnant. I take a lot of food such as milk, eggs, meat, and veggies. I think, it might help me to get high gestational weight gain. When I know that I have a low level of Hct. I still take a lot of food and I don't focus on iron-rich foods. I think, if I take more food (general foods), my weight will gain. It's quite significant for me. Frankly, I did not concern about my Hct level. Sometimes, I forgot to take an iron supplement." ( $\mathrm{G}_{1} \mathrm{P}_{0}$, Age 24 years, GA 36 wk., Hb 10.4 g/dL)

Pregnant women also expressed their experiences that iron-rich foods and iron supplements might not benefit to treat IDA. They perceived iron supplements for all pregnancy, not specifically for IDA during pregnancy.

"I'm not sure about nutrients in the iron supplements that I got from hospital. I take it following the prescription but I didn't see the outcomes. I still have low Hct level both the previous

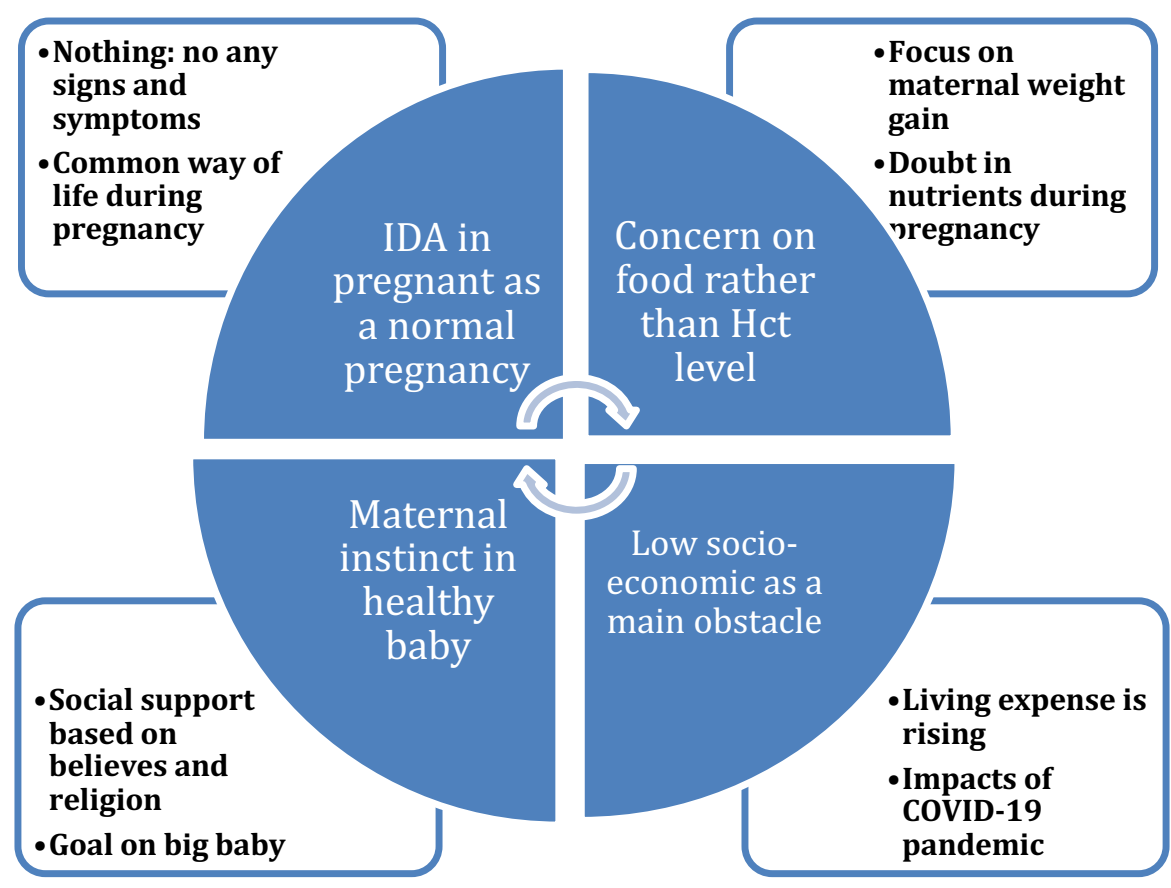

Figure 1. Themes and sub-themes of pregnant women with IDA 
and this time. Does it really help?" $\left(\mathrm{G}_{2} \mathrm{P}_{1} \mathrm{~A}_{0} \mathrm{~L}_{1}\right.$, Age 29 years, GA 31 wk., Hb 8 g/dL)

\section{Sub-theme 2.1: Focus on maternal weight gain}

Pregnant women focus on their gestational weight gain.

"It's my experience, the first pregnancy I had was normal Hct level but my weight gain was only 9 kilograms in total. My first baby, it's quite smallest just 2,600 grams. Then, I have anemia in the second pregnancy. My total gestational weight gain is 1516 kilograms, baby birth weight is 3,200 grams. It's quite a difference. If you have anemia and don't have anemia during pregnancy, it may not impact on the different size of the baby." $\left(\mathrm{G}_{3} \mathrm{P}_{2} \mathrm{~A}_{0} \mathrm{~L}_{2}\right.$, Age 35 years, GA 32 wk., Hb 7.8 g/dL)

They stated that they desired to take a lot of food. They believed that food benefits for them to gain their gestational weight.

"I have anemia during this pregnancy. So, I try to take a lot of food, such as milk, eggs, and fruits. I believe that it's good for me and my baby." $\left(\mathrm{G}_{2} \mathrm{P}_{0} \mathrm{~A}_{1} \mathrm{~L}_{0}\right.$, Age 22 years, GA 29 wk., Hb 7.8 g/dL)

They pointed out that they did not concern about iron-rich foods and iron supplements. They assumed that it's might not be an advantage for them during pregnancy.

"I still believe you are what you eat in foods rather than iron-rich foods or iron supplements such as pork liver, pork blood, green beans, and vitamin supplements. If I take only pork liver, pork blood, green beans, etc., and Obimin AZ and Ferrous Fumarate every day, my weight might not gain. It's quite bad for me and baby. I think, all pregnant women should gain their total gestational weight around 10-15 kilograms even though you have anemia. Hct level is less significant for me. It means iron-rich foods or iron supplements are less significant than my weight gains." $\left(\mathrm{G}_{2} \mathrm{P}_{1} \mathrm{~A}_{0} \mathrm{~L}_{1}\right.$, Age 38 years, GA 33 wk., Hb 8 g/dL)

"When I have anemia, I must take more food for gaining my weight." ( $\mathrm{G}_{1} \mathrm{P}_{0}$, Age 21 years, GA 31 wk., $\mathrm{Hb} 8.5 \mathrm{~g} / \mathrm{dL}$ )

\section{Sub-theme 2.2: Doubt in nutrients during pregnancy}

Pregnant women indicated that iron-rich foods and iron supplements might benefit for increasing the $\mathrm{Hct} / \mathrm{Hb}$ level but might not be of benefit for them.

"I don't know about the nutrients or iron in the ironrich foods and iron supplements. I got Ferrous Fumarate $200 \mathrm{mg}$. to treat anemia. I regularly take it three times a day: morning, noon, and evening from 12 weeks of gestation until now. The level of Hct quite swings. I mean up and down and up and down between Hct 28-31 vol\%." ( $\mathrm{G}_{4} \mathrm{P}_{3} \mathrm{~A}_{0} \mathrm{~L}_{3}$, Age 36 years, GA 32 wk., Hb 10 g/dL)
They showed that they did not know about the real benefits of iron nutrients in iron-rich foods and iron supplements. They also expressed that they hesitated about nutrients during pregnancy, especially iron.

"I feel confused about nutrients during pregnancy. I have a question as to how much iron does a pregnant woman need daily? I got Triferdine and Ferrous Fumarate. I take Triferdine one tablet once a day and Ferrous one tablet three times a day. I try to eat pork blood soup most of the week. When I checked up my Hct level, it's the same level. I don't know what's happened?" $\left(\mathrm{G}_{1} \mathrm{P}_{0}\right.$, Age 16 years, GA 27 wk., Hb 6.5 g/dL)

\section{Theme 3: Maternal instinct in healthy baby}

Pregnant women pointed out about their maternal instinct on a healthy baby. They claimed that the characteristics of a healthy baby consisted of good appearances, no complications and birth weight more than 3,000 grams. The most significant aspect of a healthy baby is big baby.

"I try to do the best. If you have a big baby, it shows you have good food and self-care during pregnancy.

You try to compare the big and small baby. The small baby might to get more frequently sick than the big baby." ( $\mathrm{G}_{3} \mathrm{P}_{2} \mathrm{~A}_{0} \mathrm{~L} 2$, Age 35 years, GA 32 wk., $\mathrm{Hb} 7.8 \mathrm{~g} / \mathrm{dL}$ )

Pregnant women supposed that they get social support based on the Thai context, belief and religion.

"My husband finds a lot of information from his family, friends and internet and prays for my baby every day, when he knows I have anemia. I try to do everything, if I can for my baby." $\left(\mathrm{G}_{1} \mathrm{P}_{0}\right.$, Age 34 years, GA 30 wk., Hb 9 g/dL)

\section{Sub-theme 3.1: Social support based on beliefs and religion}

Social support was illustrated by pregnant women that assisted them to be a healthy mom based on the Thai context, including beliefs and religion.

"He (my husband) extremely believes what his mother and grandmother give me about local food to decrease my anemia. It's is a local vegetable; it's called "Pak Good" (Paco fern or small vegetable fern). He also prays before bedtime every day. Maybe average five days a week." $\left(\mathrm{G}_{1} \mathrm{P}_{0}\right.$, Age 34 years, GA 30 wk., Hb 9 g/dL)

Informational support from healthcare professional indicated that pregnant women got an overview on IDA such as diagnosis, causes, signs and symptoms, treatment, consequences, and follow up.

"The nurse at the antenatal clinic told me in the first visit that I have anemia, Hct $24 \mathrm{vol} \%$, and gave me information about causes, signs, protocol for treatment and impacts on me and the baby. Then, I met the doctor. She said I need to get blood transfusion and then take a blood test after that. I 
have had iron supplements since after blood transfusion until now." $\left(\mathrm{G}_{1} \mathrm{P}_{0}\right.$, Age 17 years, GA 32 wk., $\mathrm{Hb} 9 \mathrm{~g} / \mathrm{dL}$ )

\section{Sub-theme 3.2: Goal of a big baby}

Pregnant women claimed their goal of pregnancy was that they wanted to get a big baby. They do the best to gain high gestational weight during pregnancy. Based on their belief and Thai context, pregnant women expressed their experiences that having a big baby came from their parents and grandparents.

"My aim is to get a baby birth weight more than 3,500 grams. I'm not sure, is it quite high? But my mom and my grandmother told me you should take more foods to have a baby more than 3.5 kilograms. It's a healthy baby." $\left(\mathrm{G}_{1} \mathrm{P}_{0}\right.$, Age 21 years, GA $32 \mathrm{wk}$., $\mathrm{Hb} 9.8 \mathrm{~g} / \mathrm{dL}$ )

"In Thailand, if you have a big baby that means you are healthy during pregnancy and have a healthy boy too. Most people don't concern about what Hct level do you have during pregnancy. They also ask you as a common question: How much weight did you gain during pregnancy and how does your baby weigh?" ( $\mathrm{G}_{1} \mathrm{P}_{0}$, Age 22 years, GA 33 wk., Hb 8.2 $\mathrm{g} / \mathrm{dL})$

\section{Theme 4: Low socioeconomics as a main obstacle}

The socioeconomic aspects showed that pregnant women concerned about their income and monthly stipend during pregnancy. Pregnant women illustrated that they worried about cost of vitamin supplements and others during pregnancy with IDA. It is a main barrier to pregnant women regarding IDA.

"I still keep money for my family rather than for myself although I have an IDA during pregnancy. I think, the iron supplement that I got from the clinic is quite enough for me and my context. I have two children. I don't want to pay more for iron-rich food. I ate a lot of rice noodles with curry no meat. It helps me to gain my weight." $\left(\mathrm{G}_{4} \mathrm{P}_{2} \mathrm{~A}_{1} \mathrm{~L}_{2}\right.$, Age 42 years, $\mathrm{GA}$ 34 wk., Hb 8 g/dL)

"I cannot do my job. I work at the local restaurant. I have not enough money to pay for iron-rich food. I focus on living expenses in each month during the COVID-19 pandemic." ( $\mathrm{G}_{1} \mathrm{P}_{0}$, Age 19 years, GA 27 wk., $\mathrm{Hb} 10 \mathrm{~g} / \mathrm{dL}$ )

\section{Sub-theme 4.1: Living expenses rising}

Pregnant women expressed the living expenses are constantly rising in Thailand due to the impacts from the Thai socioeconomics, political situations and COVID-19 pandemic. They indicated that they got the same rate of salary, but the cost of living is rising, such as the price of pork meat, vegetables, milk, and gas for car or motorcycle. They have limited money to take care of their pregnancy with IDA.

"I concern on our living expenses (my husband, son and daughter and me). The price of pork meat, green beans, tomatoes and milk are rising. I think, it's not good if I spend too much money for my pregnancy. I try to keep a balance. So, I take care of my pregnancy the same as previous pregnancy although this pregnancy has an IDA. I choose sticky rice with fish sauce to eat rather than milk, salad, or noodle soup. I have no choice." $\left(\mathrm{G}_{4} \mathrm{P}_{3} \mathrm{~A}_{0} \mathrm{~L}_{3}\right.$, Age 36 years, GA 32 wk., Hb 10 g/dL)

\section{Sub-theme 4.2: Impacts of COVID-19 pandemic}

Participants indicated that the COVID-19 pandemic impacts on the lifestyle and their work. Some pregnant women changed their work outside to work from home. In addition, their income was decreased around $30-75 \%$. They also expressed that they have adapted their lifestyle, including their expenses. They need to take care of their pregnancy and their life also.

"I don't know how to say. I think, I cannot think about me and my pregnancy. I have not enough money because I got only 50\% of my salary from my boss due to the COVID-19 pandemic. I cannot perfectly take care of my pregnancy with IDA." $\left(\mathrm{G}_{1} \mathrm{P}_{0}\right.$, Age 23 years, GA 30 wk., Hb 8.6 g/dL)

\section{DISCUSSION}

The findings of this study reflect on their attitude, knowledge, and behavior including the selfawareness on IDA during pregnancy. Most of the pregnant women indicated that they did not have any signs and symptoms of anemia during pregnancy. They still have a common way of life as in a normal pregnancy. This experience reveals their attitudes that IDA in pregnant women is the same as a normal pregnancy. In their point of view, pregnant women with IDA and normal pregnancy got the information, treatment, and iron supplements the same as normal pregnancy. This is similar to findings of study conducted in Mumbai, India where the participants expressed their experiences of anemia as "normal during pregnancy" because they perceived weakness or fatigue might not directly impact their offspring (Chatterjee \& Fernandes, 2014). Pregnant women indicated that they were more concerned on their food intake to gain higher gestational weight rather than the severity of anemia. Based on their beliefs and Thai context, most pregnant women focused on the maternal weight gain that benefited for them and their fetuses. They also pointed out that they concerned on their general foods rather than ironrich foods and iron supplement. They revealed that they hesitated over the benefits or advantages of iron supplement or nutrients of iron-rich foods during pregnancy. These findings reflected on their low level of attitude and knowledge including the behavior of pregnant women with IDA about iron-rich foods and iron supplement. It is related to the study of factors affecting iron deficiency anemia in pregnant women that indicated the low level of knowledge and misunderstanding affecting their attitude and behavior during pregnancy, including iron 
supplements and iron-rich foods as a nutrition for pregnant women (Kaljarueg, 2017; Sookdee \& Wanaratwichit, 2016; Sukkai \& Khiewyoo, 2012).

The self-care during pregnancy with IDA was expressed that they concerned on their food intake rather than iron-rich foods and iron supplements. It might impact on their Hct or $\mathrm{Hb}$ level. They also believed that if they take a lot of food it will be good so that they have high total gestational weight gain. Participants indicated that the iron supplements and iron-rich foods were not significant to treat IDA during pregnancy. They seemed to have less knowledge about the advantages of iron-rich foods and iron supplements on IDA during pregnancy and self-awareness to enhance their behavior. A previous study aimed to determine factors affecting iron deficiency anemia among pregnant women and showed inappropriate attitude of taking iron tablets and self-care about iron deficiency anemia during pregnancy, including knowledge about iron-rich foods that were significantly associated with higher rate of IDA (Sookdee \& Wanaratwichit, 2016). These findings related to maternal instinct in a healthy baby. They believed that if they were healthy during pregnancy, they will have a big baby. It illustrated their social support from their families, friends, and significant persons, including healthcare professionals based on their beliefs and religion. It is quite important for pregnant women with IDA regarding their informational and emotional supports as a facilitators during pregnancy (Bilimale et al., 2010; Chatterjee \& Fernandes, 2014; Senanayake et al., 2010).

In addition, the findings also illustrated the barriers to behavior of pregnant women regarding IDA, that is socioeconomics and political situation. The increasing living expenses and impacts of the COVID-19 pandemic, such as lockdown, should be a concern that impacts on their income and monthly stipend, especially IDA during pregnancy. They expressed that they have enough money to support the iron-rich foods and iron supplement such as milk, meat, and offal. They still take local nutrients with high calories that they believe would afford a high maternal weight gain such as sticky rice with fish sauce and rice noodles with curry without meat. It affected their baby birth weight. It is similar to findings that the COVID-19 pandemic affected income and household consumption due to income loss and unemployment (Hawkins et al., 2010; Martin et al., 2020).

These issues will be improved by the prenatal educational program for pregnant women with IDA that develops their iron supplements adherence and health behavior of pregnant women (Bilimale et al., 2010; Pipatkul et al., 2015; Senanayake et al., 2010; Sirisopa \& Pongchaidecha, 2015). The results of this study are significant for healthcare professionals, especially nursed, that should aware and take a role as a supporter during pregnancy based on informational, emotional, tangible, and appraisal supports to enhance attitude, knowledge, self- awareness, and behavior of pregnant women with IDA (Kaljarueg, 2017; Sookdee \& Wanaratwichit, 2016; Sukkai \& Khiewyoo, 2012).

\section{CONCLUSION}

The results verified to enhance better understanding the nature and perception of pregnant women on IDA, facilitators to support women for healthy behavior, and barriers to IDA in pregnancy based on a Thai context in beliefs, socioeconomics, and religion.

The findings revealed the insight of attitude and knowledge that impacts on their experiences, behavior and self-care during pregnancy with IDA. It is very useful for healthcare professionals to be aware and gain understanding of pregnant women with IDA based on their backgrounds and context. This study will be applied in clinical practice of antenatal care clinic and health promoting hospital for reconsideration of the protocol for pregnant women with IDA in terms of diagnosis, treatment, nursing care and transfer to community.

For nursing administration, the collaboration between multidisciplinary such as pharmacist, doctor and nutritionist will be established for prenatal education about IDA. In addition, the nursing clinical practice guideline (NCPG) for pregnant women with IDA will be designed based on the findings from this study and will be tested in a future clinical trial. The limitation of this study should be considered. Most of the pregnant women represented a low to medium level of education and family income, which cannot be generalized to the entire population.

\section{ACKNOWLEDGMENT}

The authors would like to thank Associate Professor Dr. Chommanard Wannapornsiri, Dean of Faculty of Nursing, Naresuan University, Thailand for her kind support. I also would like to acknowledge my deepest thanks and gratitude to Assistant Professor Dr. Raweewan Pilaikiet as a consultant for her kind support and useful advice and guidance. We also thank our colleagues for their kind support and helpful suggestions.

\section{REFERENCES}

American College of Obstetricians and Gynecologists (ACOG). (2008). ACOG Practice bulletin-Clinical management guidelines for ObstetricianGynecologists: Anemia in pregnancy. Obstetrics \& Gynecology, 112(1), 201-207.

Anney, V. N. (2014). Ensuring the Quality of the Findings of Qualitative Research: Looking at Trustworthiness Criteria. Journal of Emerging Trends in Educational Research and Policy Studies (JETERAPS), 5(2), 272-281.

Baillie, L. (2015). Promoting and evaluating scientific rigour in qualitative research. Nursing Standard, 29(46), 36-42.

Bilimale, A., Anjum, J., Sangolli, H.N., \& Mallapur, M. (2010). Improving adherence to oral iron 
supplementation during pregnancy. Aust Med J, 3(5281-90).

Braun, V. \& Clarke, V. (2006). Using thematic analysis in psychology. Qualitative Research in Psychology. 3(2), 77-101.

Bureau of Nutrition, Department of Health, M. of P. H. (2011). Nutritive values of Thai foods. Department of Health, Ministry of Public Health.

Camaschella, C. (2015). Iron-deficiency anemia. New England Journal of Medicine, 372(19), 1832-1843.

Center of Disease Control (CDC). (1989). CDC Criteria for anemia in children and childbearing-aged women. MMWR Morbidity and Mortality Weekly Report, 138(22), 400-404.

Chatterjee, N., \& Fernandes, G. (2014). "This is normal during pregnancy": A qualitative study of anaemia-related perceptions and practices among pregnant women in Mumbai, India. Midwifery, 30(1), e56-e63.

Creswell, J. W. (2014). Research Design: Qualitative, Quantitative and Mixed Methods Approaches (4th ed.). SAGE Publications.

Department of Health, M. of P. H. (2017). Health data centre for standard on maternal and child care service of Department of Health, Ministry of Public Health. http://www.hpc.go.th/director/data/ standardUpload/LR_profile_090217_105208.pdf

Department of Health, M. of P. H. (2018). Standard of care on maternal and child service of Department of Health, Ministry of Public Health. http://www.hpc. go.th/director/data/standardUpload/LR_profile_ 090217_105208.pdf.

Food Division, Bureau of Food, Food and Drug Administration, M. of P. H. (2016). Knowledge of food and nutrition for all ages. Food and Drug Administration.

Goonewardene, M., Shehata, M., \& Hamad, A. (2012). Anemia in pregnancy. Best Practice \& Research Clinical Obstetrics and Gynaecology, 26(1), 3-24.

Hawkins, R.B., Charles, E.J., \& Mehaffey, J. H. (2010). Socioeconomic Status and Coronavirus Disease 2019 (COVID-19) Related Cases and Fatalities. Public Health. https://doi.org/https://doi.org/ 10.1016/j.puhe.2020.09.016

Holloway, I., Wheeler, S., \& Holloway, I. (2010). Qualitative research in nursing and healthcare: Chichester (3rd ed.). Blackwell.

Kaljarueg, P. (2017). Anemia among pregnant women at U-Thong Community hospital, U-Thong district, Suphanburi province. Nursing Journal of the Ministry of Public Health, 27(1), 22-32.

Lowdermilk, D.L., Perry, S.E., Cashion, K., \& Alden, K. . (2016). Maternity \& Women's health care (11th ed.). Elsevier.

Maha, S.S., Tondare, S.B., \& Tondare, M. . (2011). Study of impact of anemia on pregnancy. International Journal of Reproduction, Contraception. Obstetrics and Gynecology, 6(11), 4847-4850.

Martin, A., Markhvida, M., Hallegatte, S. \& Walsh, B. (2020). Socio-Economic Impacts of COVID-19 on
Household Consumption and Poverty. Economics of Disasters and Climate Change, 4, 453-479. https://doi.org/https://doi.org/10.1007/s41885 -020-00070-3

Murray-Kolb, L.E., Chen, L., Chen, P., Shapiro, M., \& Caulfield, L. (2012). CHERG Iron report: Maternal mortality, child mortality, perinatal mortality, child cognition, and estimates of prevalence of anemia due to iron deficiency. CHERG.

Pinchaleaw, D. (2017). Nurses and management of iron deficiency anemia in pregnant women. Journal of the Police Nurses, 9(2), 195-201.

Pipatkul, W., Sinsuksai, N., \& Phahuwatanakorn, W. (2015). Effects of a nutrition and iron supplement promoting program on iron deficiency anemia in pregnant women. Journal of Nursing Science, 33(1), 69-76.

Reinold, C., Dalenius, K., Brindley, P., Smith, B., \& Grummer-Strawn, L. (2012). Pregnancy nutrition surveillance 2008 report. U.S.Department of Health and Human Service.

Senanayake, H.M., Premaratne, S.P., Palihawadana, T., \& Wijetrat, S. (2010). Simple educational intervention will improve the efficacy of routine antenatal iron supplementation. J Obstet Gynaecol Res, 36(3), 646-650.

Shenton, A. (2004). Strategies for ensuring trustworthiness in qualitative research projects. Education for Information, 22(2), 66-67.

Sirisopa, N. \& Pongchaidecha, M. (2015). Evaluation of a Pharmaceutical care program with pregnant women with Iron deficiency anemia. Journal of Science \& Technology, Ubon Ratchathani University, 17(2), 53-62.

Sookdee, J., Wanaratwichit, C. (2016). Factors affecting iron deficiency anemia among pregnant women receiving antenatal care at sub-districts health promoting hospital. Journal of Health Science Research, 10(1), 1-7.

Sukkai, C., Khiewyoo, J. (2012). Factors related to anemia among pregnant women in Khaopanom district, Krabi province. Srinagarind Med J, 27(2), 133-138.

Tana, C. (2017). Anemia in pregnancy. http://www.med.cmu.ac.th

Tandon, R., Jain, A., \& Malhorta, P. (2018). Management of Iron deficiency anemia in preganancy in India. Indian Journal of Hematology Blood Transfusion, 34(2), 204-215.

Techakampholsarakit, L., Kantaruksa, K., \& Sansiriphun, N. (2018). Interventions to promote anemia prevention among pregnant women: A systemic review. Nursing Journal, 45(1), 62-74.

WHO. (2011). Haemoglobin concentrations for the diagnosis of anaemia and assessment of severity. WHO.

WHO. (2012). The Global Prevalence of Anemia in 2011. WHO.

WHO. (2016). WHO recommendations on antenatal care for a positive pregnancy experience. WHO. 